\title{
Superdiversity and conviviality: exploring frameworks for doing ethnography in Southern European intercultural cities
}

\author{
Beatriz Padilla, Joana Azevedo and Antonia Olmos-Alcaraz
}

(Received 6 September 2013; accepted 25 September 2014)

\begin{abstract}
International migration contributes to increasing cultural diversity in many European cities. Historically, migration studies have focused on the integration of immigrants foregrounding race/ethnicity and identity issues, limiting our understanding of intercultural diversity. A new paradigm focusing on relational patterns among groups is emerging, highlighting the importance of mutual relations, interactions and influences among residents of different origins and backgrounds, including the experience of both immigrants and autochthonous populations. The notions of superdiversity and conviviality have significantly contributed to this debate. This paper discusses how both were methodologically operationalized in multi-sited ethnographies carried out in Lisbon and Granada, during 2009-2012. Superdiversity and conviviality are the main theoretical frameworks used to understand how interculturality is lived and experienced at the local level. We reflect on their strengths and weaknesses, unpacking common assumptions about race, ethnicity and culture, specifically looking at the negotiation of difference in intercultural events.
\end{abstract}

Keywords: superdiversity; conviviality; ethnography; interculturality; Lisbon; Granada

As a consequence of international migration, diversity has become a key feature of European societies. At the local level, cities simultaneously celebrate and reject diversity. Growing concerns with racism and xenophobia compete with a preoccupation with tolerance, civility and intercultural dialogue. Hostile sentiments towards immigrants have become more common especially in the wake of the European economic crisis (Hainmueller and Hiscox 2007); however, paradoxically, it simultaneously is recognized that diversity brings cultural and economic opportunities. Most policies aimed at incorporating foreigners into host societies have barely succeeded in altering negative views, as shows, for example, the European Social Survey, which pinpoints how Europeans regard immigrants with distrust and as a threat to 'European values' of equality and liberty (Card, Dustmann, and Preston 2005).

The dynamics of intercultural interactions remain poorly understood (Wood, Landry, and Bloomfield 2006). Most studies about immigrants are confined to measuring the level of 'integration', assessing 'separately' how immigrants of different backgrounds are doing, and how much or how little they integrate into host societies. In general, studies presumed assimilation, reifying issues of identities 


\section{B. Padilla et al.}

and ethnicities while ignoring or downplaying the importance of interactions, exchange and interpersonal relations between migrants and the host society. While much headway has been made in the name of transnationalism, neither identities nor ethnicities have been useful enough to grasp the real meaning of 'living together' in diverse contexts (Brubaker 2004).

This paper discusses the methodological aspects and challenges emerging from a project aimed at understanding conviviality in so-called superdiverse cities in Southern Europe, namely Lisbon and Granada. We reflect on the strengths and weaknesses of using the frameworks of conviviality (Gilroy 2004) and superdiversity (Vertovec 2007) in multi-sited ethnographies, analysing how these concepts respond when operationalized in the field. We approached actors' interactions through an 'intercultural lens', hoping to overcome previous limitations, and chose ethnographic tools, mainly participant observation and interviews, to produce multi-situated ethnographies. Because this is a methodological reflection, we do not develop all three ethnographies but give some hints.

The article begins with a presentation of the frameworks guiding the research. Then, we briefly discuss why we chose multi-sited field sites, focusing thereafter on the profiles and imaginaries about diversity in those field sites located in Lisbon and Granada. Next, we outline the methodological and analytical strategy developed to study conviviality in superdiverse contexts. Finally, we discuss the discourses and practices of diversity in intercultural events as one empirical example of the application of our strategy, closing with final thoughts about studying diversity in contemporary intercultural cities by merging the perspectives of superdiversity and conviviality.

\section{Theoretical framework and methodological implications}

Conviviality and superdiversity, two notions challenging previous approaches based on identity and ethnicity, guided our original research. We asked if they were two sides of the same coin, or instead, captured different aspects of diversity in contemporary societies. Both conviviality and superdiversity approaches have been used in different ways: as theoretical frameworks (guiding what is being studied), as methodological tools, as a way to approach the field (how to capture the object under investigation), and as concepts to describe a given reality (whether a context is superdiverse).

Paul Gilroy questioned the static boundaries of race/ethnicity/culture and the ambiguity of identity, stressing the relational aspects of human encounters. For him, conviviality designates the:

process[es] of cohabitation and interaction that have made multiculture an ordinary feature of social life in Britain's urban areas and in postcolonial cities elsewhere.... It introduces a measure of distance from the pivotal term "identity", which has proved to be such an ambiguous resource in the analysis of race, ethnicity, and politics. (Gilroy 2004, xi) 
Gilroy hoped to overcome 'race thinking' derived from conceptions of homogeneity and sameness rooted in colonial imaginaries, by acknowledging the existing (super) diversity and heterogeneity of current societies. He focused on 'the ordinary experiences of contact, cooperation, and conflict across the supposedly impermeable boundaries of race, culture, identity and ethnicity' (Gilroy 2004, xii), arguing for a 'cosmopolitan solidarity' based on grass-roots humanity. However, he did not provide clues on how to empirically grasp conviviality, leaving this decision to the methodological imagination of the researcher.

For Vertovec, superdiversity is a means of overcoming limitations encountered by focusing on ethnicity, and

to underscore the fact that in addition to more people now migrating from more places, significant new conjunctions and interactions of variables have arisen through patterns of immigration to the UK over the past decade; their outcomes surpass the ways - in public discourse, policy debates and academic literature - that we usually understand diversity in Britain. (Vertovec 2007, 1025)

Commonplace interactions need to be studied further in order to identify the negative and positive reactions that they bring - for example, 'animosities, fears, competition' (Vertovec 2007, 1045) or friendships, vicinity, solidarity.

Conviviality and superdiversity both refer to multicultural contemporary Britain. Our project applied these concepts to new immigration contexts in Southern Europe where intercultural models instead of multicultural ones have been adopted. For this exercise, we incorporated other useful concepts and perspectives to grasp and complement superdiversity and conviviality, including quotidian diversity, intersectionality and critical interculturality.

Quotidian diversity stresses that issues of power are intrinsically related to living together. 'Power relations are always present in place sharing as are various degrees of intolerance and cross-cultural discomfort' (Wise 2009, 42), shaping the way that people interact or appropriate the shared public and private spaces, mainly when it involves relations across migration-related differences. By recognizing power asymmetries in contexts of alterity, intersectionality (Knudsen 2006) helped us to trace how 'certain people seem to get positioned as not only different but also troublesome and, in some instances, marginalized' (Staunæs 2003, 101), varying according to situation and context.

While Vertovec, Gilroy and Wise provided methodological tools for the research, the notion of critical interculturality ideologically sustained the geopolitics of place and space as a de-colonial approach pertinent for considering peoples of diverse backgrounds who are perceived as subaltern or disenfranchised. In Walsh's (2009) perspective, interculturality has two meanings: one functional (institutional strategy that promotes dialogue and coexistence without addressing the causes of inequalities) and another political (that questions the system; Walsh [2010]). However, in this work, we can only address the first one, implying a dialogue among diversities. Diversities are understood as the multiple features of societies - origin, language, race/ethnicity, gender, age and social class, among others - in which immigration is 
the common denominator and trigger of new/old interactions, reactions and relations. The following shows how these concepts were operationalized.

\section{Multi-sited ethnographies}

Between 2009 and 2012, two teams carried out in-depth qualitative research. Because diversity is spread unevenly across the territory within a city, becoming manifest in different convivialities, we privileged local and comparative approaches, opting for multi-sited ethnographies. Indeed, this reflects one concern of superdiversity as linked to residential choices and length of residence (Vertovec 2007, 135). muti-sitedness in our project operated on three levels. First we chose two metropolitan areas in two different Southern European countries: Lisbon (a national capital) and Granada (a regional capital). Second, two different areas were singled out within each: Mouraria and Cacém in Lisbon; Realejo and Zaidín in Granada. One area was located in the centre and the other on the periphery, and each represented neighbourhoods with: (1) a prevalent social and community fabric (e.g. local associations); (2) diverse populations in terms of ethnicity, gender, age, origin, including native and immigrant populations; and (3) low residential segregation. Third, three mini-ethnographies were carried out in each neighbourhood around three foci: (1) interactions among neighbours in public spaces; (2) youth learning about diversity and conviviality both in formal (schools) and less formal institutions (associations and after-school programmes); and (3) intercultural events as manifestations of cultural policies and practices at the local level. Each mini-ethnography captured different local realities about quotidian interactions and how intercultural relations took place.

\section{Lisbon and Granada: imaginaries and profiles of diversities}

Both Lisbon and Granada share imaginaries of diversity that have been produced and reproduced throughout history, creating myths of peaceful cultural coexistence. Lisbon and Granada are marked by their history of mixing, blending and conquests of territories and peoples, including Romans, Moors, Christians and Jews. In both cities, we found local discourses highlighting mixed backgrounds and 'living together'. Yet, in each, the imaginary of convivial diversity was elaborated differently, producing mini-visions of the studied areas: Mouraria and Cacém in Lisbon, and Realejo and Zaidín in Granada. The downtown sites shared common features of historic districts, including a history of mixing and long-term degradation, followed by a process of renewal, rehabilitation and gentrification. The sites in the suburbs included aspects associated with the growth and expansion of poorly planned cities, the (re)location of newcomers from within the country and abroad, located far from the opportunities and conveniences that cities provide.

While an easy-to-read table facilitating the comparison of our four field sites would be desirable, recent changes in counting and classifying migrants in the two national and four local contexts, and the unavailability of data about the many dimensions of superdiversity (cf. De Bock, this issue), prevents such an exercise. The following thus outlines the profile of each neighbourhood in turn, referring to different aspects of diversity. 
In Lisbon, city marketing and the new cultural strategy evoke 'mixture', promoting diversity and conviviality as the city's asset. In 2011, Lisbon was recognized as an intercultural city by the Council of Europe. With a population of about 545,000, Lisbon has expanded, giving rise to a metropolitan area with eighteen municipalities and a total population of approximately 3 million. With more than $50 \%$ of the total immigrant population in Portugal living in the Lisbon Metropolitan Area, immigrants are now an ordinary aspect of urban life. According to the 2012 Report of the Portuguese Foreigners and Frontier Services (SEF 2013), the two neighbourhoods studied are located in municipalities with high concentrations of foreign-born residents: Lisbon and Sintra. In Lisbon (municipality), where Mouraria is located, immigrants represent $8.1 \%$ of the total population, while in Sintra they represent $9.5 \%$.

Although the current economic crisis has reversed the inflow and outflow of immigrants, official documents of the Municipality of Lisbon praise and claim diversity as follows:

Lisbon is (and has always been) a city of many cultures, which have been subject to simultaneous processes of miscegenation and individualization.... The Lisbon Municipality hopes to potentiate this vocation and multicultural identity through the promotion of intercultural or transcultural projects that offer spaces and opportunities for cultural encounters and sharing among people of different nationalities, ethnicities, creeds and genders, as well as specific intervention projects in problematic neighbourhoods. (Costa 2009, 112)

Mouraria is one of the most diverse neighbourhoods. A long-term resident and community leader explained how, over time, Mouraria has experienced the arrival of different migration waves that led to changes in the composition of its population. Some of the immigrants came for entrepreneurial purposes, opening retail trade stores, furniture import-export businesses, ethnic restaurants or food stores. In the mid1970s, Indo-Portuguese (Muslim and Hindu) migrants arrived; then, during the 1990s, migrants came from Guinea-Bissau and Cape Verde, as well as from Senegal and Zaire. More recently, people of diverse origins and creeds such as Pakistanis, Bangladeshis and Chinese have settled, as well as students and artists of different EU backgrounds, making Mouraria a superdiverse space with migrants not just from many places but also with many different migration trajectories (Fonseca et al. 2012).

The neighbourhood is experiencing a rehabilitation process that is changing the profile and social fabric of the population. Moreover, immigrants represent about 25\% of residents, indicating different settlement patterns even within the social space considered.

Cacém, located in the Municipality of Sintra, is part of the Lisbon Metropolitan Area. According to the 2011 census, this territory has a population of 57,113 inhabitants, approximately $10 \%$ of which are foreign born. Approximately $84 \%$ arrived from African countries. Citizens from Brazil, Romania and Ukraine constitute most of the new arrivals. This diversity has expanded over time, becoming first visible in the 1970s with decolonization and more evident after Portugal joined the EU. 
Granada is a medium-sized city in south-eastern Spain, with a population of approximately $250,000 .{ }^{1}$ Immigrant populations have decreased from $9.8 \%$ to $6.7 \%$, due to the economic recession over the last few years (Aja, Arango, and Oliver Alonso 2011). In recent decades, the diversity of backgrounds among the foreign-born population has increased significantly to include Moroccans, Romanians, Senegalese and Ecuadorians. This process has revived the collective imagination around Granada as a 'diverse city' that welcomes newcomers.

The district of Realejo is part of the historical centre of Granada. Since the 1990s, the neighbourhood has changed, mainly due to urban renewal and real estate speculation, which led to the expulsion of low-income Spanish residents and attracted well-off residents from other EU countries. Yet, the spirit of diversity lives on. As one resident put it: 'This neighbourhood is mixed... we have always been open people... newcomers are very welcome!' Realejo has a total population of $16,158,12 \%$ of which are foreign born. New arrivals come mainly from America (33\%), followed by Europe (29\%), Africa (25\%) and Asia (10\%). In Granada, this accounts for a high percentage of Europeans. Realejo attracts young professionals without children and a large university student population, but it is also home to an older autochthon population.

Zaidín is a suburb of Granada, established in the 1960s as a working-class neighbourhood. Migrants, mainly from sub-Saharan Africa and Latin America, only started arriving in the 1990s. Later, North Africans and Eastern Europeans also settled there (Rodriguez and Salguero 2009). The neighbourhood still maintains its workingclass character and has not been stigmatized by members of the host society. Despite the presence of foreigners, residents do not evoke diversity in their narratives. According to the 2011 census, the total population of Zaidín is 47,253, being the second-largest district of Granada, and having the second-highest concentration of immigrants (approximately 14\%). The main nationalities are Moroccans and Ecuadorians. Almost half of the male immigrant population comes from Africa, while almost $50 \%$ of female migrants from Latin America.

Even if the profiles of these four neighbourhoods illustrate different types of diversities, only those located downtown in central districts, Mouraria and Realejo, adopt imaginaries of conviviality within diversity in their discourses, using them in a marketable cosmopolitan way. In the suburbs of Cacém and Zaidín, diversity is not mobilized as a resource by locals or the public authorities. Thus, in our research we observed how visible diversity has become desirable for city marketing and worldwide competition (Salzbrunn 2008) for downtown neighbourhoods in what has been defined as a process of cosmopolitanization embedded in global interdependency (cf. Hannerz 1990; Delanty 2005), while diversity on the outskirts is not celebrated.

The selected areas present similarities and differences regarding their imaginaries and population profiles, when comparing downtown and peripheral neighbourhoods in Lisbon and Granada. In Cacém and Zaidín, located on the outskirts of these cities, the views about diversity are mainly associated with poverty and exclusion. In Cacém, it is negatively related to segregation, deviant behaviours and crime, because migration is viewed as a 'problematic phenomenon'. By contrast, the neighbourhoods of Mouraria and Realejo, located in the downtown historic districts, strategically use a 
convivial imaginary that embraces diversity in different ways - for tourism, attraction of newcomers, ethnic business and the promotion of creative initiatives, therefore moving beyond migration as a problem and adopting a vision of migration as a resource. The complexities of the diversities described posed methodological challenges and required strategies for resolving them; this is the focus of the remainder of this article.

\section{Methodological tools for studying convivialities in superdiverse contexts}

A primary methodological challenge was defining a common procedure for data collection and data comparison, given the complexity of the areas under study. Prior to data collection, the Lisbon and Granada research teams designed common specific protocols of observation, as well as guides for semi-structured interviews. The purpose was to define not simply common questions, but a common perspective on how to approach the field and study convivialities (Padilla and Azevedo 2012). Our main concern and challenge was to move beyond the study of migrant groups, broadening the 'lens' to understand the diversities of the areas in their multiple levels and meanings, motivated both by ideas from superdiversity and conviviality.

Fieldwork comprised different levels of participant observations and interviews with selected key actors. Confronted with the broadness and complexity of the selected areas, we reorganized the field, subdividing it into a set of nine research dimensions to capture the main neighbourhood features and relevant aspects of diversity (for our purpose) (see Table 1). We then described and compared these dimensions across neighbourhoods.

Next, we focused on operationalizing the convivial dimension of that framework. Table 2 presents a systematization of the conviviality settings found in the explored areas. We must underline that transversally, in each setting or type of context economic, cultural, educational, and so on - we observed different forms of conviviality, including tensions and conflicts.

Moreover, we acknowledge that Table 2 is one way to understand and organize the observed reality. Our approach has analytical and instrumental aims and we are aware of the limitations that a typology implies; however, we opted for this as the potential of systematizing and categorizing is valuable for making sense of complex realities such as the ones we found. These two tables complement each other, mixing superdiversity features (i.e. age, gender, origin, language, religion, migration status, etc.) with conviviality dimensions and settings, bringing together the contributions from both frameworks.

Conviviality and superdiversity have mainly been used and developed as theoretical concepts; however, our project attempted to advance their empirical application. By working with these theoretical and methodological frameworks, we faced some challenges.

The first challenge lay in defining what accounts for superdiversity - moving beyond superdiversity as defined by ethnicity. Superdiversity required a broad interpretation of diversities that made it inclusive of all aspects and intersectional categories (i.e. immigrants and non-immigrants, class, gender, generations, etc.). So, on the one hand, it is true that cities like Lisbon and Granada have among their main 
Table 1. Diversity research dimensions.

\begin{tabular}{|c|c|c|}
\hline General dimensions & Research dimensions & Relevant aspects of diversity \\
\hline \multirow[t]{2}{*}{ Actors } & Immigrants & $\begin{array}{l}\text { - Origin } \\
\text { - Age } \\
\text { - Occupation } \\
\text { - Descendants } \\
\text { - Waves and lengths of } \\
\text { settlement }\end{array}$ \\
\hline & Autochthonous & $\begin{array}{l}\text { - Age } \\
\text { - Generational gap } \\
\text { - Occupation } \\
\text { - Class }\end{array}$ \\
\hline \multirow[t]{2}{*}{ Social networks } & $\begin{array}{l}\text { Associations/community } \\
\text { organizations }\end{array}$ & $\begin{array}{l}\text { - Share of migrants } \\
\text { - Scope and types of } \\
\text { initiatives }\end{array}$ \\
\hline & Kinship networks & $\begin{array}{l}\text { - Types } \\
\text { - Degree of endogamy }\end{array}$ \\
\hline \multirow[t]{5}{*}{$\begin{array}{l}\text { Neighbourhood } \\
\text { characteristics }\end{array}$} & Mobility trend & $\begin{array}{l}\text { - White flight } \\
\text { - Gentrification } \\
\text { - Requalification }\end{array}$ \\
\hline & Local economy & $\begin{array}{l}\text { - Ethnic } \\
\text { - Traditional } \\
\text { - Innovative/creative } \\
\text { - Transnational }\end{array}$ \\
\hline & Religious diversity & $\begin{array}{l}\text { - Types } \\
\text { - Relations among groups } \\
\text { - Practices } \\
\text { - Places of worship }\end{array}$ \\
\hline & Cultural features & $\begin{array}{l}\text { - Types of cultural activities } \\
\text { - Scale } \\
\text { - Intercultural dimension }\end{array}$ \\
\hline & Policies & $\begin{array}{l}\text { - Urban } \\
\text { - Social } \\
\text { - Economic }\end{array}$ \\
\hline
\end{tabular}

features the diversification of their migrant populations; but on the other hand, their superdiverse features are also marked by different elements that could be ethnic but also cultural, economic and political. Moreover, these features should be considered at the local level.

Based on the assumption that conviviality refers not only to positive aspects of social interactions, but also encompasses less positive encounters, the second challenge consisted of understanding and capturing how interchanges between diverse populations occur in a given context on a daily basis. Quotidianization of relations makes immigrant presence a normal feature of everyday life. For example, students of immigrant origin are no longer viewed as 'the other' by their colleagues or teachers in Cacém's schools. In the words of a resident in Realejo: 
Table 2. Conviviality settings.

\begin{tabular}{|c|c|}
\hline Conviviality dimensions & Main diversity features (description, details) \\
\hline Economic and consumptions & $\begin{array}{l}\text { - Traditional business, shopping centres and surroundings } \\
\text { - Quotidian shopping and consumptions } \\
\text { - Ethnic and cosmopolitan shopping and consumptions } \\
\text { - Retail sales }\end{array}$ \\
\hline Touristic & $\begin{array}{l}\text { - Restaurant and bars itineraries } \\
\text { - Organized neighbourhood visits } \\
\text { - Pedestrian visitors } \\
\text { - Fado/flamenco routes and similar initiatives }\end{array}$ \\
\hline Sociocultural & $\begin{array}{l}\text { - Encounters in public space (streets and squares, etc.) } \\
\text { - Cultural initiatives } \\
\text { - Interventions by associations and public authorities } \\
\text { - Social or sports programmes } \\
\text { - Non-residents' encounters with neighbours }\end{array}$ \\
\hline Religious & $\begin{array}{l}\text { - Attendance to cult } \\
\text { - Diversity of cult sites } \\
\text { - Neighbourhood engagement of religious organizations } \\
\text { - Cross-participation in processions and other religious } \\
\text { festivities }\end{array}$ \\
\hline Educational & $\begin{array}{l}\text { - School initiatives/events } \\
\text { - Classes } \\
\text { - Informal mingling during school breaks } \\
\text { - Specific programmes for foreigners/descendants } \\
\text { - Special activities on conviviality and conflict }\end{array}$ \\
\hline $\begin{array}{l}\text { Intercultural events and } \\
\text { policies }\end{array}$ & $\begin{array}{l}\text { - Cultural policies celebrating diversity } \\
\text { - Neighbours' involvement in initiatives } \\
\text { - Local authorities' participation } \\
\text { - Artists' work within the neighbourhood } \\
\text { - Associations' involvement } \\
\text { - Outsiders' and tourists' contact with neighbourhood }\end{array}$ \\
\hline Conflicts and tensions & $\begin{array}{l}\text { - Drugs (trafficking and use), prostitution, delinquency, gangs } \\
\text { - Quotidian conflicts (smells, noises, refuse disposal, etc.) } \\
\text { - Different use of public space and daily schedules }\end{array}$ \\
\hline
\end{tabular}

[diversity] is not a discriminating factor here, it is a reality that you become aware and enjoy, from the cultural point of view. I work here, have breakfast everyday at Carlos cafeteria, buy a shawarma from the Syrian guys in the Plaza Fortuny or a vegetarian meal in the small kiosk.

On the other hand, tensions were related to different aspects of diversity and conviviality, not only ethnicity. In Realejo, neighbours complained about squatters living in overcrowded houses; in Mouraria, about drug dealers and addicts consuming in the open space; in Cacém, about Roma families living in the hallways of the buildings.

A third challenge refers to conviviality as mediated by power relations. Defining a research strategy implied recognizing power issues as transversal categories of 
convivialities. This dimension could best be captured in the study of intercultural events in the neighbourhoods and we thus foreground this research dimension in the remainder of this paper. We cannot expand our discussion within the scope of this paper to include the other two axes studied in this project - teaching of diversity and neighbourhood interactions. However, this one example already allows insights into how our research strategy translated in the field.

By observing the meetings of city hall authorities and neighbourhood organizations prior and during cultural events, we were able to understand actual practices, making it possible to identify different visions of diversity, the power dynamics between groups, and the specific policies promoted. We make reference to these in the next section.

Keeping the aforementioned challenges in mind, we built a novel methodological strategy. In sum, conviviality was used as a relational approach of interactions and interchanges among diverse individuals (conviviality dimensions), while superdiversity privileged the identification of the main features of diversity in contemporary intercultural cities (see Tables 1 and 2).

\section{Interculturality, discourses and practices to manage diversity}

In this section, we show how our methodological strategy advanced our understanding of local convivialities promoted through cultural policies by looking in more detail at one of our empirical axis - the social dynamics around intercultural events. Ethnographic fieldwork has shown that cultural policies reach their objectives by action or omission (Oliveira and Padilla 2012). Being a participant observer during the planning stage and the actual celebration (event), as well as gathering information through in-depth interviews with the various actors involved (e.g. association leaders, cultural programmers, public servants, authorities and politicians), was fundamental in our methodology for uncovering competing visions, practices and dynamics of power relations in the neighbourhoods under investigation. Intercultural events took place in three of our four neighbourhoods. We thus now focus on findings from three mini-ethnographies, each illustrating a specific type of intercultural event (out of many): a bottom-up organized event (Granada); a top-down mandatory event (Cacém); and a top-down participatory event (Mouraria).

Granada's XVI Fiesta por la Interculturalidad - Acercando personas construimos ciudadanía took place in May 2011 and was a bottom-up event, planned at the city level mainly by a human rights organization that invites immigrant associations and other community organizations to take part. Coincidentally, it took place in Realejo in 2011, but it usually alternates across neighbourhoods. This Fiesta, attended by migrants and local residents, was built around folklore manifestations, privileging identity ascriptions based on race, ethnicity or foreign nationality, but favouring sociality. It openly discouraged tourist participation, seeking to foster conviviality among residents to break stereotypes, even if interculturality was understood as an exotic cultural manifestation of the other. Through participant observation, we observed how non-governmental organization staff and immigrants shared spaces and carried out join activities (art, craft and music workshops) in an egalitarian environment. 
Cacém lacked its own local celebration, but the Municipality of Sintra created Immigrants' Day to celebrate diversity, starting in 2008 during the European Year of Intercultural Dialogue. Public officials centralized the organization, expecting the involvement of officially recognized immigrant associations as a duty. Associations freely chose a performance for the event, but neither members nor neighbours were mobilized to get involved; moreover, non-immigrants were not expected to be involved as participants or audience. The celebration remained self-contained and was held in a closed public space, where participants could be 'controlled' and external visibility could be minimized. Interculturality was a folkloristic mix of music, language and dance classes; yet, gastronomic expressions were prohibited due to rules pertaining to the youth house that hosted the event. Because involvement was almost compulsory for immigrant associations, we named it a top-down mandatory event. A city councilwoman said:

The municipal Immigrant's day is to show the work developed by the immigrant communities residing here, the most numerous ones. ... The aim was to value immigrant groups, which of course are related to the African communities, those that imply a cultural shock

In her view, the work of the immigrant groups is to be shown among themselves, not to the larger community. And even if different African communities settled decades ago, they still 'imply a cultural shock' - in other words, not constituting a quotidian positive element in the neighbourhood.

Mouraria hosted the Festival Todos (Walk of Cultures), which took place in the core of the neighbourhood and was organized by the Municipality of Lisbon with the collaboration of local associations, local authorities (freguesias) and professional cultural programmers. Immigrant communities were consulted but not present in the planning. Todos included a hectic schedule of cultural events, carried out in the streets and other social venues (i.e. a sports pavilion and cultural centres). The five-day programme encompassed music, a theatre piece, a photo exhibition of/with neighbours, puppets for children, ping-pong tables, fado performances, and more. Participants ranged from neighbours of all ages (autochthonous and immigrant) and residents from other neighbourhoods, to tourists and artists who enjoyed and consumed 'culture'. Here, interculturality was understood as a path to promoting knowledge and dialogue among autochthonous and immigrant cultures, but selected cultural manifestations had to meet the 'high-quality' standards of the cultural programmers, who hired known artists from home and abroad, in search of a marketable celebration. As involvement was endorsed, we named it a top-down participatory event. Many of the activities planned for the festival promoted interactions among neighbours. One example was the photo session and exhibition that invited the elderly to guide a neighbourhood tour telling the stories of the residents, autochthonous and immigrant, fostering a sense of belonging and community. The head of the culture office explained: 'For me interculturality is not only about foreigners in Lisbon, it is about letting others know about Lisbon and Lisbon's culture. ... the idea is to travel around the world without leaving Lisbon.' 
Even if, for reasons of space, we are unable to provide more ethnographic details, our data (summarized in Tables 1 and 2) suggest that the intercultural policy dimension can enable and limit intercultural convivialities. The three visions identified above - bottom-up, top-down mandatory and top-down participatory view and promote cultural policies and intercultural dialogue differently. In addition, we witnessed how the renewal of public spaces and the existence of particular sociospatial configurations mediated the emergence of different forms of conviviality, promoting more inclusive or exclusive forms in the use of public spaces.

Our initial typology of conviviality settings considering different aspects of superdiversity allowed us to recognize and make sense of the observed intercultural events. Analysing them is relevant for mapping and interpreting diversity, which for the most part transcend mere leisure-entertaining aims to become privileged platforms of where to observe convivialities. Thus, intercultural events, even if conceived to recreate a certain type of diversity (e.g. ethnic, folkloristic, cosmopolitan), may also become emerging spaces to explore new dynamics of superdiversity, allowing the recognition of power relations between the actors involved and the identification of the different ways that diversity is celebrated or downplayed.

\section{Final reflections}

In this paper we offered reflections on methodological and analytical aspects for the study of diversity and the dynamics of conviviality in superdiverse contexts. Preliminary reflections allow us to pinpoint some methodological considerations. Our ethnographic experience showed that it is possible to combine the frameworks of conviviality and superdiversity. Also, it showed that in order to move forward, it is central to understand both frameworks in a way that transcends the mere definition of race/ethnicity/culture/identities. Even if both hoped to overcome this, most studies using them still adopt these as overarching categories. In this sense, conviviality and superdiversity gain from becoming more holistic. By focusing on relations and interactions in conviviality settings and by including all population backgrounds in addition to age, gender, social class, length of residence and legal status, among others, within the features of superdiversity, we believe to have modestly solved this contradiction. Otherwise, research will continue to contribute to more ethnicization, reproducing divisions that are later carried into social interactions. Also, fieldwork showed us that conflicts are not only defined by ethnicity and race, but are embedded in social relations.

As a consequence, the study of 'superdiverse convivialities' as promoting interculturality should be framed as a way to contest the reproduction of otherness. It is important to be aware of the evolving changes and of the dynamics embedded in the contexts under consideration, which imply transformations in the definition of who migrants and native populations are; if this is not observed, superdiversity and conviviality will always mean otherness. The quotidianization of interactions plays an important role in understanding diversity. Our data show that in hybrid spaces, heterogeneity is common and experienced on a daily basis, such that 'difference/ otherness' is internalized and may be transformed into a quotidian positive feature. 
Beyond presenting a multi-situated case study located in two Southern European cities and thus adding to the empirical study of superdiversity and conviviality, this paper has not only contributed to a merging dialogue between both concepts, but we were able to inform their operationalization at the methodological and analytical level. Approaching the field with a tool or grid to unpack complex realities identified in conviviality settings in superdiverse contexts may assist future research studying diverse glocalities, crossing spaces of convivialities and aspects of visible and invisible diversities.

\section{Acknowledgements}

The authors would like to thank the anonymous reviewers, the Ethnic and Racial Studies editor, and the guest editors, Fran Meissner and Steve Vertovec, for their useful comments on a previous draft of this article.

\section{Funding}

This article is part of the study 'Convivial Cultures and Super-diversity' (2010-2012), undertaken at the CIES-IUL, Lisbon University Institute (Portugal), and the LDEI, Universidad de Granada (Spain), supported by the Portuguese National Science Foundation, FCT [PTDC/ CS-SOC/101693/2008].

\section{Note}

1. Data from the Spanish National Statistics Institute (2011) (http://www.ine.es).

\section{References}

Aja, Eliseo, Joaquín Arango, and Josep Oliver Alonso, eds. 2011. Inmigración y crisis económica. Impactos actuales y perspectivas de futuro. Anuario de la inmigración en España [Immigration and Economic Crisis. Current Impacts and Future Perspectives. Immigration in Spain Yearbook Series]. Barcelona: Bellaterra Edicions.

Brubaker, Rogers. 2004. Ethnicity without Groups. Cambridge, MA: Harvard University Press. Card, David, Christian Dustmann, and Ian Preston. 2005. "Understanding Attitudes to Immigration: The Migration and Minority Module of the First European Social Survey." CReAM Discussion Paper No 03/05. Accessed June 2014. http://www.cream-migration.org/ publ_uploads/CDP_03_05.pdf

Costa, Pedro, ed. 2009. Estratégias para a Cultura em Lisboa [Strategies for Culture in Lisbon]. Lisbon: Câmara Municipal de Lisboa.

Delanty, Gerard. 2005. "The Idea of a Cosmopolitan Europe: On the Cultural Significance of Europeanization." International Review of Sociology 15 (3): 405-421. doi:10.1080/ 03906700500272434.

Fonseca, Maria Lucinda, Jennifer McGarrigle, Alina Esteves, Dora Sampaio, Rui Carvalho, Jorge Malheiros, and Luis Moreno. 2012. Modes of Inter-ethnic Coexistence in Three Neighbourhoods in the Lisbon Metropolitan Area: A Comparative Perspective. Lisbon: Colibri / Centro de Estudos Geográficos.

Gilroy, Paul. 2004. After Empire: Melancholia or Convivial Culture? London: Routledge. 
Hainmueller, Jens, and Michael J. Hiscox. 2007. "Educated Preferences: Explaining Attitudes Toward Immigration in Europe." International Organization 61: 399-442. doi:10.1017/ S0020818307070142.

Hannerz, Ulf. 1990. "Cosmopolitans and Locals in World Culture." In Global Culture. Nationalism, Globalization and Modernity, edited by Mike Featherstone, 237-251. London: Sage Publications.

Knudsen, Susanne V. 2006. "Intersectionality - A Theoretical Inspiration in the Analysis of Minority Cultures and Identities in Textbooks." In Caught in the Web or Lost in the Textbook?, edited by Éric Bruillard, Bente Aamotsbakken, Susanne V. Knudsen, and Mike Horsley, 61-75. Accessed June 2014. http://iartemblog.files.wordpress.com/2012/03/8th_iartem_2005-conference.pdf

Oliveira, Nuno, and Beatriz Padilla. 2012 "A diversidade como elemento de desenvolvimento/ atração nas políticas locais urbanas: contrastes e semelhanças nos eventos de celebração intercultural [Diversity as an Element of Development/Attraction in Local Urban Policies: Contrasts and Similarities in Intercultural Events]." Sociologia, Revista da Faculdade de Letras da Universidade do Porto 22: 129-162.

Padilla, Beatriz, and Joana Azevedo. 2012. "Territórios de diversidade e convivência cultural: Consideraçõ es teóricas e empíricas [Territories of Diversity and Conviviality: Theoretical and Empirical Considerations]." Sociologia, Revista da Faculdade de Letras da Universidade do Porto [Sociologia, Revista da Faculdade de Letras da Universidade do Porto] 22: 43-67.

Rodriguez, Juan, and Óscar Salguero. 2009. Aprendiendo a decir NO. Conflictos y resistências en torno a la forma de concebir y proyectar la ciudad de Granada [Learning to Say NO. Conflicts and Resistance on How to Conceive and Project the City of Granada]. Granada: Asociación de Estúdios Antropológicos La Corrala.

Salzbrunn, Monika. 2008. "World Society, Transnationalism and Champs Migratoires: Reflections on German, Anglo-Saxon and French Academic Debates." In The Making of World Society. Perspectives from Transnational Research, edited by Remus Gabriel Anghel et al., 75-100. Bielefeld: Transcript/Transaction Publishers.

SEF. 2013. Relatório de Imigração Fronteiras e Asilo - 2012 [Report on Immigration, Frontiers and Asylum]. Lisbon: Serviço de Estrangeiros e Fronteiras.

Staunæs, Dorthe. 2003. "Where Have All the Subjects Gone? Bringing Together the Concepts of Intersectionality and Subjectification." NORA 2: 101-110.

Vertovec, Steven. 2007. "Super-diversity and its Implications." Ethnic and Racial Studies 30 (6): 1024-1054. doi:10.1080/01419870701599465.

Walsh, Catherine. 2009. Interculturalidad, Estado, Sociedad. Luchas (de)coloniales de nuestra época [Interculturality, State and Society. (De)colonial Struggles of Our Time]. Quito: Universidad Andina Simón Bolívar/AbyaYala.

Walsh, Catherine. 2010. "Development as Buen Vivir: Institutional Arrangements and (de) colonial Entanglements." Development 53 (1): 15-21. doi:10.1057/dev.2009.93.

Wise, Amanda. 2009. "Everyday Multiculturalism: Transversal Crossings and Working Class Cosmopolitans." In Everyday Multiculturalism, edited by Amanda Wise and Selvaraj Velayutham, 21-45. Houndmills: Palgrave-Macmillan.

Wood, Phil, Charles Landry, and Jude Bloomfield. 2006. Cultural Diversity in Britain A Toolkit for Cross-cultural Co-operation. New York: Joseph Rowntree Foundation.

BEATRIZ PADILLA is Associate Professor at the Department of Sociology at the Institute of Social Sciences of the University of Minho.

ADDRESS: Universidade do Minho, ICS - Sociologia, Campus de Gualtar, 4710-057 Braga, Portugal. Email: padilla.beatriz@gmail.com 
JOANA AZEVEDO is Postdoctoral Fellow in the Centro de Investigação e Estudos de Sociologia (CIES-IUL) at the Instituto Universitário de Lisboa (ISCTE-IUL).

ADDRESS: CIES-IUL, Instituto Universitário de Lisboa (ISCTE-IUL), Av. Das Forças Armadas, 1649-026 Lisbon, Portugal. Email: joana.azevedo@iscte.pt

ANTONIA OLMOS-ALCARAZ is Lecturer in the Department of Social Anthropology at the University of Granada (Spain).

ADDRESS: Facultad de Filosofía y Letras, Campus de Cartuja, s/n, Granada, 18071, Spain. Email: antonia@ugr.es 